\title{
Pintahygienia tuorekasviksia prosessoivissa laitoksissa
}

\author{
Risto Kuisma ${ }^{I)}$, Marja Lehto ${ }^{2}$, Jenni Määttä ${ }^{I)}$, Maarit Mäki ${ }^{3}$, Hanna-Riitta Kymäläinen ${ }^{l)}$ \\ ${ }^{1)}$ Helsingin yliopisto, Maataloustieteiden laitos, PL 28 (Koetilantie 3), 00014 Helsingin yliopis- \\ to, risto.kuisma@helsinki.fi, jenni.maatta@helsinki.fi, hanna-riitta.kymalainen@helsinki.fi \\ ${ }^{2)}$ MTT Kotieläintuotannon tutkimus, Vakolantie 55,03400 Vihti, marja.lehto@mtt.fi, \\ ${ }^{3)}$ MTT Biotekniikka- ja elintarviketutkimus, Alimentum,31600Jokioinen, maarit.maki@mtt.fi
}

\section{Tiivistelmä}

Kasvisten käsittely on lisääntynyt viime vuosina eri puolilla maailmaa. Samaan aikaan useiden ruokamyrkytysepidemioiden tartuntalähteeksi ovat osoittautuneet tuoreet, kuumentamattomat kasvikset. Kasviksissa on luonnostaan varsin paljon mikrobeja ja ne ovat lisäksi herkkiä sadonkorjuun jälkeiselle mikrobiologiselle kontaminaatiolle korkean vesi- ja ravinnepitoisuutensa takia. Kontaminoituminen voi tapahtua tuotannon kaikissa vaiheissa. Kasviksia käsittelevät yritykset ovat olleet kiinnostuneita prosessien kehittämisestä. Tutkimuksen tavoitteena oli selvittää kasviksia käsittelevien laitosten hygieenistä tasoa sekä tunnistaa kriittiset pisteet tuotannossa ja tuotantotiloissa. Tuotantotilojen ja prosessilaitteiden pintojen hygieeninen taso tutkittiin erilaisilla nopeilla hygienianmääritysmenetelmillä normaalin puhdistuksen jälkeen otetuista pintanäytteistä. Aerobisten mikrobien, enterobakteerien ja $\beta$ glukuronidaasi-entsyymejä tuottavien lajien sekä hiivojen ja homeiden kokonaismäärän määritykseen käytettiin Hygicult ${ }^{\circledR}$-kontaktilevyjä. Eloperäisestä liasta ja mikrobikontaminaatiosta peräisin oleva ATP mitattiin pinnoilta luminometrisesti. Lisäksi tutkittiin sisäilman aerobisten mikrobien kokonaismääriä. Sisäilman näytteenotossa käytettiin MAS-100 -keräintä. Korkeimmat aerobisten mikrobien, enterobakteerien ja ß-glukuronidaasi-entsyymejä tuottavien lajien sekä hiivojen kokonaismäärät todettiin koneiden (leikkurit, paloittelukoneet jne.) pinnoilta. Suurin osa näistä laitteista on kosketuksissa raaka-aineiden tai pakkaamattomien tuotteiden kanssa. Korkeita eloperäisen kontaminaation määriä mitattiin joidenkin pakkausten ja leikkureiden pinnoilta. Erityisesti puisissa pakkauslaatikoissa oli runsaasti eloperäistä likaa. Suurin osa pinnoilta mitatuista bakteerimääristä ylitti suomalaisessa pintahygieniaoppaassa esitetyt viitearvot. Tulosten tarkastelun yhteydessä tulisi kuitenkin ottaa huomioon eri tuotantolaitosten tyypit ja tuotannon vaiheet. Puhtausvaatimukset kasvistenkäsittelylaitoksen eri toiminnoissa vaihtelevat; korkeamman hygienian alueen puhtausvaatimukset ovat tiukemmat kuin alhaisemman hygienia-alueen, esimerkiksi kasvisten pesulinjan, vaatimukset. Tästä huolimatta tulokset osoittivat, että tuorekasvisten tuotannossa on selkeä tarve parantaa puhdistus- ja hygieniakäytäntöjä. Tutkimuksen jälkeen tuotantolaitosten johtoa opastettiin kiinnittämään enemmän huomiota laitoksen puhtaanapitoon, tuotantoalueiden suunnitteluun, työntekijöiden koulutukseen ja omavalvontaan.

Asiasanat: kasvikset, tuorevihannekset, hygienia, valvonta, puhtaus, puhdistuvuus, mikrobiologinen laatu 


\section{Johdanto}

Tuoreena syötävistä kasviksista Suomessa yleisimmin käytettyjä ovat erilaiset vihreät salaatit ja porkkana. Kasviksia prosessoidaan yhä pidemmälle ja uusia kasvistuotteita tulee markkinoille koko ajan. Kuluttajat ja suurkeittiöt haluavat vaivatonta ruuanlaittoa ja yhä pitemmälle jalostettuja raaka-aineita. Kasvisten tuottajien toiminnan monipuolistuminen ja uudet tehtävät tuovat mukanaan monia haasteita. Työntekijöitä, tuotantotilaa sekä koneita ja laitteita tarvitaan lisää, tilojen ja laitteiden puhdistukseen tarvitaan resursseja ja osaamista. Tuotannon kasvaessa myös omavalvontaan täytyy lisätä resursseja. Viime vuosina elintarvikealalla on noussut erityisen huomion kohteeksi tuorekasvisten turvallisuus, koska useiden ruokamyrkytystapausten lähteeksi on todettu tuoreet kasvikset. Esimerkiksi Yersinia pseudotuberculosis -bakteeri oli aiheuttajana useassa raakojen porkkanoiden välittämässä epidemiassa Suomessa 2000-luvulla. Y. pseudotuberculosis on ihmiselle patogeeninen (tautia aiheuttava) ympäristöbakteeri (Rimhanen-Finne ym. 2009). Mikrobit ovat usein lähtöisin jo pellolta. On tärkeää, että prosessoitava raaka-aine on korkeatasoista. Tuoreet kasvikset sisältävät mikrobeja ja oikealla käsittelyllä voidaan varmistaa tuotteiden turvallisuus koko elintarvikeketjussa.

Elintarvikkeiden tuottajilla on EU:n säädösten mukaan ensisijainen vastuu elintarviketurvallisuudesta. Tuotantolaitoksissa on määritettävä todennäköisimmät mahdollisten taudinaiheuttajien ja muiden tuotteita pilaavien mikrobien lähteet ja leviämisreitit. Tuotantotilojen sisällä epäpuhtaus siirtyy useimmiten raaka-aineiden, tuotteiden ja muiden materiaalivirtojen sekä työntekijöiden ja ilman mukana. Tuotantohygienian kannalta on tärkeää estää epäpuhtauksien siirtyminen epähygieenisemmästä tilasta hygieenisempään tilaan ja pinnoille. Raaka-aineet voivat toimia tuotteiden mikrobiologisen kontaminaation aiheuttajina. Tuote voi myös kontaminoitua mikrobeilla prosessoinnin ja pakkauksen aikana, mikäli laitteistojen ja koneiden pinnat eivät ole riittävän puhtaita. Koneet ja laitteet voivat olla hygienian kannalta huonosti suunniteltuja, niissä voi olla hankalasti puhdistettavia rakenteita tai niissä on käytetty materiaaleja, jotka keräävät likaa ja ovat vaikea puhdistaa ja desinfioida käytön jälkeen.(Wirtanen 2002, Korkeala 2007).

\section{Aineisto ja menetelmät}

Kasvisprosessien hygieniaa selvitettiin MTT:n ja Helsingin yliopiston yhteistyönä toteutettavassa, Tuotevihannesten hygienia (Tuovi) -hankkeessa. Hygieniakartoitukset tehtiin kasviksia prosessoivissa laitoksissa, joissa kasvikset pestään, kuoritaan ja pilkotaan erilaisiksi tuorekasvistuotteiksi. Mukana oli yrityksiä, jotka sekä tuottavat raaka-aineen että prosessoivat sen valmiiksi tuotteiksi, sekä yrityksiä, jotka jatkojalostavat esikäsiteltyä raaka-ainetta erilaisikis salaateiksi ym. tuotteiksi. Kasviksia jatkojalostavien yritysten hygieniatason määrittämiseksi ja ongelmakohtien selvittämiseksi haastateltiin ensin yrityksen henkilökuntaa. Näytteenottokohdat dokumentoitiin ja valokuvattiin. Tämän pohjalta tehtiin varsinainen näytteenottosuunnitelma, jonka mukaisesti hygieniakartoitus toteutettiin. Jatkojalostuslaitoksen yksilölliset piirteet pyrittiin ottamaan huomioon näytteenottosuunnitelmissa. Kuudesta laitoksesta otettiin normaalin päivittäisen puhdistuksen jälkeen näytteitä noin 600 pinnalta, joista suurin osa oli elintarviketuotannon aikana kosketuksissa pakkaamattomaan tuotteeseen.

Pinta- ja ympäristönäytteiden lisäksi otettiin raaka-aine- ja tuotenäytteet mikrobiologisia tutkimuksia varten (Lehto ym. 2011). Ilman ja pintojen hygieenistä tasoa tutkittiin erilaisilla määritysmenetelmillä. Orion Diagnostican Hygicult@ TPC -kontaktilevyjä käytettiin aerobisten mikrobien kokonaismäärän määritykseen. Hygicult ${ }^{\circledR}$ E/B-Gur -kontaktilevyjä käytettiin enterobakteerien ja ßglukuronidaasi-entsyymejä tuottavien lajien kokonaismäärän määritykseen. Escherichia coli kannoista $90 \%$ on B-glukuronidaasiaktiivisia. Myös Salmonella, Edwardsiella, Shigella ja Yersinia ovat B-glukuronidaasia tuottavia lajeja. Hygicult ${ }^{\circledR} \mathrm{Y} \& \mathrm{~F}$-kontaktilevyjä käytettiin hiivojen ja homeiden kokonaismäärän määritykseen. Pintojen ATP mitattiin luminometrisesti HY-LiTE®2-laitteella (Merck KgaA, Saksa). Ilmassa olevien mikrobien lukumäärän määritykseen käytettiin MAS-100 keräintä (Merck Eurolab). Tulosten tulkinnassa käytetyt raja-arvot ja viitteet tulosten luokittelemiseksi on esitetty taulukossa 1. 
Taulukko 1. Raja-arvot ja viitteet pintahygieniatulosten tulkinnassa.

\begin{tabular}{lllll}
\hline Mikrobiryhmä & Hyvä & Välttävä & Huono & Viite \\
\hline Kokonaismikrobit & $<2 \mathrm{pmy} / \mathrm{cm}^{2}$ & $2-10 \mathrm{pmy} / \mathrm{cm}^{2}$ & $>10 \mathrm{pmy} / \mathrm{cm}^{2}$ & Rahkio ym. 2006 \\
Hiivat & $<1 \mathrm{pmy} / \mathrm{cm}^{2}$ & $1-5 \mathrm{pmy} / \mathrm{cm}^{2}$ & $>5 \mathrm{pmy} / \mathrm{cm}^{2}$ & Hakala 2001 \\
Homeet & $-/+$ & ++ & +++ & Orion Diagnostica, \\
& $($ Ei yhtään/ vähäinen & (Kohtalainen määrä & (Suuri määrä & käyttöohje 2008 \\
& määrä hometta) & hometta) & hometta) & \\
Enterobakteerit ja $\beta-$ & 0 pmy/cm & & \\
GUR & & $0,1-1,1 \mathrm{pmy} / \mathrm{cm}^{2}$ & $>1,1 \mathrm{pmy} / \mathrm{cm}^{2}$ & $\begin{array}{l}\text { Orion Diagnostica, } \\
\text { käyttöohje 2008 }\end{array}$ \\
\hline
\end{tabular}

pmy = pesäkettä muodostava yksikkö

\section{Tulokset ja tulosten tarkastelu}

Yrityksissä tehdyissä hygieniakartoituksissa havaittiin, että varsinkin erilaisten laitteiden ja pintojen puhdistettavuuteen sekä tuotantotilojen säännölliseen ja perusteelliseen puhdistukseen sekä desinfiointiin tulisi kiinnittää erityistä huomiota. Yritysten välillä oli selviä eroja toiminnassa, toimintatavoissa, tiloissa ja prosesseissa. Myös hygieniataso vaihteli yritysten välillä. Kuvioissa 1 ja 2 sekä taulukossa 2 on esitetty kooste hygieniakartoitusten tuloksista (Lehto ym. 2011). Korkeimmat kokonaismikrobimäärät, hiivojen, enterobakteerien ja $\beta$-glukuronidaasipositiivisten bakteerien määrät sekä korkeimmat ATP-arvot mitattiin koneiden ja laitteiden pinnoilta. Korkeat ATP-arvot mitattiin myös kuljetinhihnojen pinnoilta sekä pinnoilta, jotka eivät olleet tuotteen kanssa kosketuksissa. Enterobakteerien, hiivojen ja homeiden esiintyminen tuotteiden kanssa kosketuksissa olevilla pinnoilla muodostaa riskin tuoteturvallisuudelle Hygieniakartoitusten tulosten perusteella tulisi kiinnittää erityisesti huomiota pintojen ja tilojen puhdistukseen sekä tehostaa omavalvontaa ja lisätä näytteenottopisteitä ja -tiheyttä.

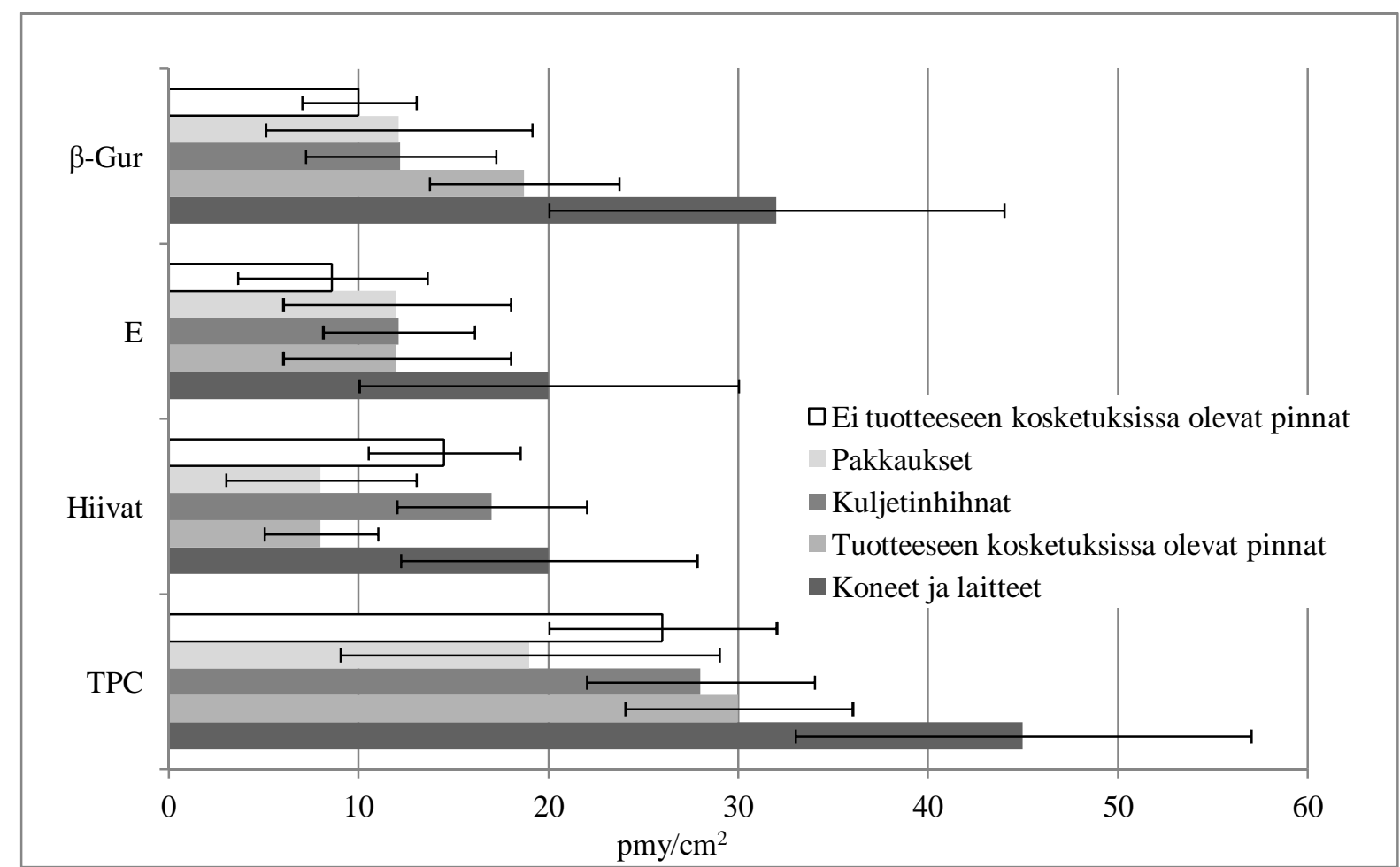

Kuvio 1. Tulokset Hygicult-kastolevyillä tehdyistä pintojen mikrobiologisista puhtausmäärityksistä. Tulokset ovat keskiarvoja eri laitoksissa tehdyistä mittauksista. 


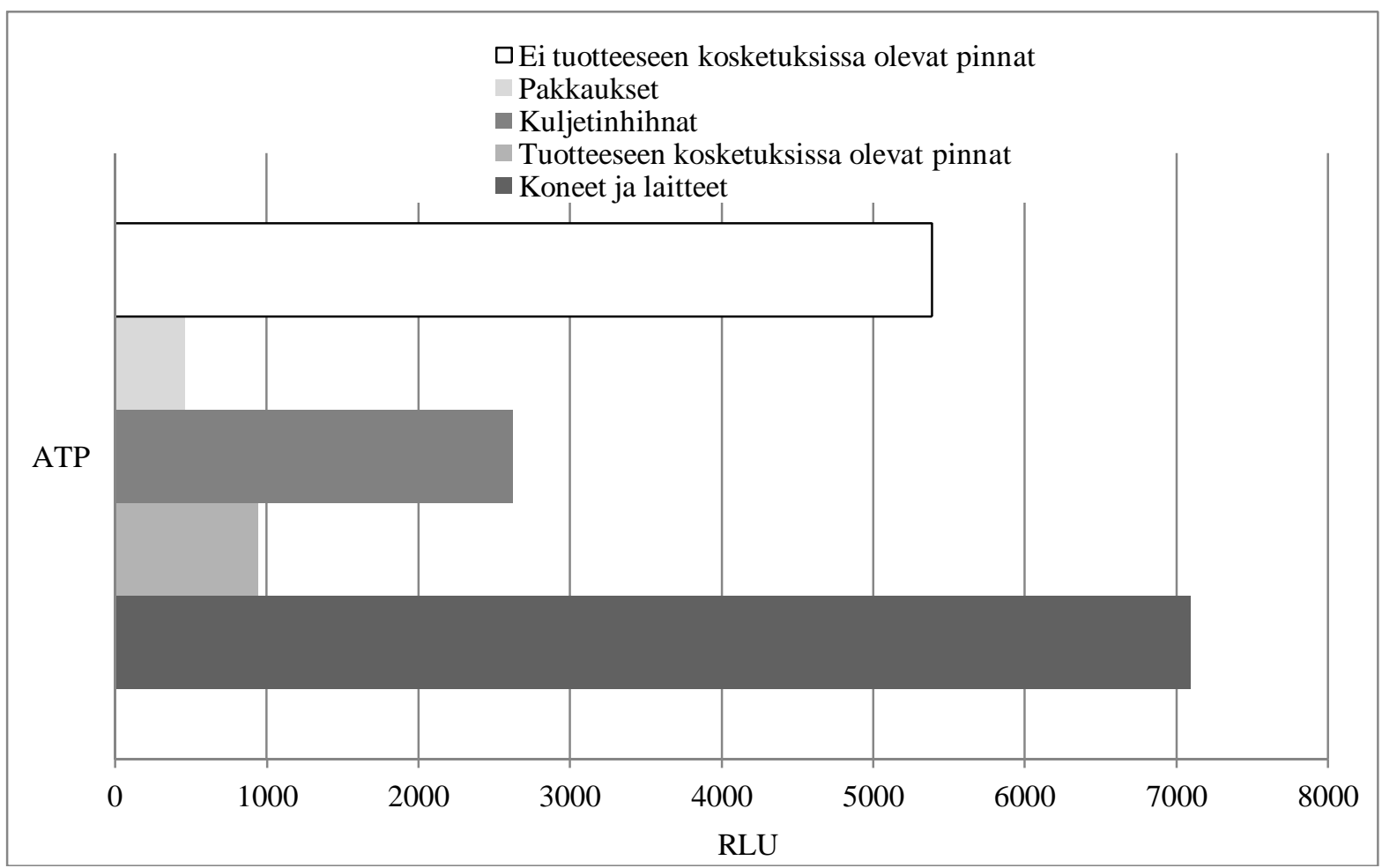

Kuvio 2. Yhteenveto ATP-bioluminesenssituloksista. RLU = suhteellinen valoyksikkö (relative light unit). Tulokset ovat keskiarvoja eri laitoksissa tehdyistä mittauksista.

Ilmamittauksissa korkeimmat mikrobimäärät mitattiin yhdestä jatkojalostusyrityksen välivarastosta, jossa esikäsitellyt kasvikset oli varastoitu ennen varsinaista prosessointia (Lehto ym. 2011). Korkeita pitoisuuksia (>1000 $\mathrm{pmy} \mathrm{m}^{-3}$ ) mitattiin myös tuotantotilasta, kuorimosta, valmistuotevarastosta ja porkkanapakkaamosta (taulukko 2).

Taulukko 2. Ilmanäytteiden aerobisten mikrobien kokonaismäärien keskiarvot ja keskihajonnat (pmy $\mathrm{m}^{-3}$ ). Tulokset ovat keskiarvoja useassa laitoksessa tehdyistä mittauksista.

\begin{tabular}{lll}
\hline Mittauspaikka & Keskiarvo & Keskihajonta \\
\hline Ulkoilma & 608 & 106 \\
Lähettämö & 642 & 740 \\
Raaka-ainevarasto & 792 & 760 \\
Tuotantotila & 1132 & 122 \\
Kuorimo & 1080 & 119 \\
Valmistuotevarasto & 1460 & 220 \\
Porkkanapakkaamo & 1254 & 140 \\
Välivarasto & 21250 & 21849 \\
Juuresten vastaanotto ja pesu & 600 & 565 \\
Kuivavarasto & 105 & 71 \\
Jäähdytysvarasto & 103 & - \\
\hline
\end{tabular}

\section{Johtopäätökset}

Tuovi-hankkeessa tehtyjen hygieniakartoitusten perusteella annettiin kasviksia jatkojalostaville yrityksille toimintasuosituksia (Lehto ym. 2011).

Useimmissa yrityksissä tilojen ja laitteiden pesun ja puhdistuksen pitäisi olla tehokkaampaa kuin mittausten aikana. Yritykset ovat tehostaneet toimintaansa tutkimusten tulosten perusteella. Tuorekasvisten prosessoinnissa täytyy koko tuotantoketjun olla kunnossa ja hallinnassa, sillä yksikin vaihe voi pilata lopputuotteen laadun.

Hygieniatasoltaan erilaiset tilat ja toiminnot on sijoitettava eri huonetiloihin (Eviran ohje Dnro 662/32/03). Eri hygienia-alueita ovat esimerkiksi likainen porkkanoiden pesutila, jossa käsitellään multaisia raaka-aineita, ja toisaalta puhdas pakkaamo, jossa käsitellään pestyjä ja mahdollisesti prosessoituja, valmiita tuotteita. Vaihtoehtoisesti erilaiset toiminnot voidaan sijoittaa riittävän etäälle toisis- 
taan tai eri aikoina tapahtuviksi. Henkilökunnan liikkumista hygienia-alueelta toiselle tulee välttää.

Työntekijöiden koulutuksella ja työskentelytavoilla on myös merkittävä vaikutus tuotantohygieniaan ja tähän tulisi kiinnittää entistä enemmän huomiota. Esimerkiksi kädet tulee desinfioida tai käsineet vaihtaa säännöllisesti.

Tuotteet voivat likaantua myös ilman välityksellä. Ilmastointilaitteiden puhdistus samoin kuin mahdollisten suodattimien vaihtaminen tai puhdistus tulee tehdä säännöllisesti. Edestakainen liikenne osastojen välillä tulisi minimoida. Ilmanvaihdolla pyritään estämään ilman välityksellä tapahtuva kontaminaation siirtyminen tuotantotiloihin ja tilasta toiseen. Tuotantotiloista ei ihannetilanteessa ole suoraa kulkuyhteyttä ulos tai laitoksen likaisiin tiloihin. Laitoksen sisällä vallitseva lievä ylipaine estää mahdollisten ilmaperäisten kontaminanttien pääsyn laitokseen.

Työvälineiden välityksellä tapahtuva kontaminaatio voidaan ehkäistä esimerkiksi uusimalla kuluneiden leikkuutasojen pinnat ja kuljetinhihnat riittävän usein. Puhtaat ja likaiset työvälineet on säilytettävä erillään toisistaan ristikontaminaation estämiseksi. Tuotantotilassa säilytysastiat, kuten korit ja laatikot on pidettävä irti lattiasta tasoilla tai pöydillä, koska lattia väistämättä likaantuu ja kontaminaatio voi siirtyä siitä raaka-aineeseen tai valmiiseen tuotteeseen. Jos lattioita tai laitteita joudutaan pesemään tuotannon aikana, vesiroiskeet eivät saa liata tuotantolinjalla olevia suojaamattomia tuotteita. Pintojen puhdistamiseen tarvitaan yleensä sekä mekaanista työtä että puhdistus- ja desinfiointiaineita. Joidenkin kuljetinhihnojen sivu- tai alalistat ovat hyviä mikrobien kasvualustoja ja lian poisto vaatii tarkkaavaisuutta. Trukit ja kuljetusvaunutkin voivat kuljettaa likaa huoneesta toiseen, joten niiden pyörät on tarvittaessa puhdistettava ja desinfioitava. Desinfiointimattoja käytetään työntekijöiden kulkureiteillä siirryttäessä eri hygienia-alueelta toiselle. Liikuteltavia astioita, kuten koreja, laatikoita, saaveja tai laitteita ei saa tuoda alemman hygienian alueelta korkeamman hygienian alueelle ilman huolellista pesua (Korkeala 2007).

Siivousvälineet eivät saa lojua keräämässä likaa ja kasvattamassa mikrobeja, vaan niille on järjestettävä ilmava säilytyspaikka ja -telineet. Siivousvälineet on puhdistettava perusteellisesti käytön jälkeen ja annettava kuivua.

Tutkimuksessa selvitettiin kasviksia käsittelevien laitosten hygieeninen taso sekä tunnistettiin kriittiset pisteet tuotannossa ja tuotantotiloissa. Kyseiset laitokset voivat kehittää tuotantoaan hygieniakartoitusten tulosten avulla. Yrityskohtaiset toimintasuositukset on kuvattu kullekin yritykselle toimitetussa tutkimusselostuksessa.

\section{Kiitokset}

Tutkimusta rahoittavat Varsinais-Suomen ELY-keskus sekä hankkeessa mukana olevat viljelijät ja yritykset.

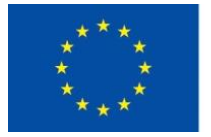

Euroopan maaseudun

kehittämisen maatalousrahasto:

Eurooppa investoi maaseutualueisiin

\section{Kirjallisuus}

Elintarvikevirasto. 2003. Puhdistusohjelma ja puhtauden tarkkailuohjelma hygienia-lain mukaisessa laitoksessa. OHJE Dnro 662/32/03

Hakala, L-L. 2001. Kasvisten prosessihygienia ja mikrobiologinen turvallisuus. Helsingin yliopisto. 89 s.

Korkeala, H. 2007. Elintarvikehygienia. Ympäristöhygienia, elintarvike- ja ympäristötoksitologia. Helsinki: WSOY. 497 s.

Lehto, M., Kuisma, R., Määttä, J., Kymäläinen, H.-R. \& Mäki, M. 2011. Hygienic level and surface contamination in fresh-cut vegetable production plants. Food Control 22, 469-475.

Orion Diagnostica. 2008. Hygicultien käyttöohjeet. Orion Dignostica Oy.

Rahkio M, Wirtanen G, Salo S, Syyrakki S, Houhala K, Levo S \& Niemi V-M. 2006. Pintahygieniaopas. Elintarvike ja Terveys-Lehti. $68 \mathrm{~s}$.

Rimhanen-Finne, R., Niskanen, T., Hallanvuo, S., Makary, P., Haukka, K., Pajunen, S., Siitonen, A., Ristolainen, R., Pöyry, H., Ollgren, J. and Kuusi, M.. 2009. Yersinia pseudotuberculosis causing a large outbreak associated with carrots in Finland, 2006. Epidemiology and Infection 137, 342-347.

Wirtanen, G. (toim.). Laitehygienia elintarviketeollisuudessa. Hygieniaongelmien ja Listeria monocytogeneksen hallintakeinot. Espoo 2002. VTT Publications 480. $183 \mathrm{~s}$. 